\title{
Ecological Social Development Model of Health Behavior of Conduct Achievement MDGs 5
}

\author{
Hilmi Yumni ${ }^{1}$, Fendy Suhariadi ${ }^{2}$, Oedojo Sudirham ${ }^{3}$, Baiq Dewi Harnani R $^{4}$, Hasyim As'ari ${ }^{5}$, \\ Noer Saudah ${ }^{6}$ \\ ${ }^{1}$ Faculty of Public Health, Airlangga University, Indonesia \\ ${ }^{2}$ Department of Organization and Industry Psychology, Faculty of Psychology, Airlangga University, Indonesia \\ ${ }^{3}$ Department of Health Promotion and Behavioral Sciences, Faculty of Public Health, Airlangga University, Indonesia \\ ${ }^{4}$ Department of Maternity, Health Polytechnic Surabaya , Indonesia \\ ${ }^{5}$ Department of Pediatric, Health Polytechnic Surabaya, Indonesia \\ ${ }^{6}$ Department of Maternity, Nursing Institute of Health Science Bina Sehat PPNI Mojokerto, Indonesia
}

\begin{tabular}{l}
\hline Article Info \\
\hline Article history: \\
Received Apr 27, 2016 \\
Revised Jul 20, 2016 \\
Accepted Aug 6, 2016 \\
\hline
\end{tabular}

Keyword:

Community

First social ecological models of health

Second behavioral achievement of MDG 5

Third intrapersonal

Interpersonal

\begin{abstract}
Behavior of pregnant women who support the achievement of MDG 5 has not been fully achieved, one antenatal visit, shows there are still pregnant women who do not perform pregnancy tests regularly. The research aims to develop a model with Social Ecological Approach Model of Health Behavior in order to achieve the Millennium Development Goals by objective 5 with indicator of antenatal visits as well as aid delivery plan both place of birth and birth attendant. Observational study design, analytic, cross-sectional sample of 100 pregnant women who visit antenatal care at the health center Krembangan South Surabaya, simple random sampling, instruments using questionnaires, data analysis descriptive and inferential, using structural equation modeling (Structural Equation Modelling). The development of the social model of ecological models of health behavior to the behavior of the achievement of MDG 5 by the dominant factor is the construction of models intrapersonal factors include knowledge, attitude and self-efficacy, interpersonal factors include the support of family and community factors include health result support model testing goodness of fit note that the resulting model is an appropriate model used in the interpretation of the model because it has a model fit the criteria of empirical data generated by the study. The model can be used to strategize interventions in antenatal care is increasing knowledge, forming attitudes and self-efficacy through various activities such as prenatal classes or groups in pregnancy exercise as well as the involvement of family and health volunteers in assisting pregnant women to childbed.
\end{abstract}

Copyright $\odot 2016$ Institute of Advanced Engineering and Science. All rights reserved.

\section{Corresponding Author:}

Hilmi Yumni,

Faculty of Public Health,

Airlangga University,

Surabaya, Indonesia.

Email: hilmiyumni@yahoo.com

\section{INTRODUCTION}

Millennium Development Goals (MDGs) are to improve maternal health indicators include the achievement of delivery assistance by skilled health personnel, health care for pregnant women, maternity and childbirth. Behaviors that can be shown to achieve these indicators are maternal antenatal health worker (antenatal care visits). Activities performed at antenatal care is integrated, among others, identify a plan to give birth in a health facility and birth attendants [1-2]. 
Current condition that the behavior of pregnant women who support the achievement of the MDG's to-5 has not been fully achieved, such as antenatal visits, shows there are still pregnant women who do not perform regular antenatal care, including first-time visits to healthcare providers, called K1 reaches $98.58 \%$, visit pregnant women for antenatal with the 1-1-4 pattern reaches $92.78 \%$. Factors identified such behavior include individual, family and health services and community. The approach used to describe behavior that can support the achievement of the MDG's 5th is through the Social Ecological Model of Health Behavior.

Research Question are the development model of socio ecological models of health behavior (intrapersonal, interpersonal and community) influence on the achievement of the MDG's 5th (antenatal visits and deliveries in the health center Krembangan South Surabaya? The research purpose in general is developing a model of Social Ecological Model of Health Behavior on behavior MDG "s 5 (Visits antenatal and childbirth assistance) at the health center Krembangan South Surabaya.

\section{RESEARCH METHOD}

Analytical research design research one step, starting with a survey of the behavior of the achievement of MDG 5 includes a visit antenatal and childbirth assistance plan, then explore the variable factors affecting the level of intrapersonal, interpersonal and community, where this variable will be used as an indicator of manifest variables models. The early models obtained through the analysis of the model, followed by the Focus Group Discussion (FGD) with the Health Department of Surabaya, Head of community health service and regional coordinator of the midwife South Krembagan Surabaya. FGD data will be analyzed from a review of strategic issues and the concept of the solution to produce prototype models that will serve as recommendations theoretical model in improving achievement of MDG's 5 behavior. Data collection was a questionnaire.

The location of this research is in the health center Krembangan South Surabaya. The population in this study were all pregnant women who visit antenatal care at the Health Center South Krembangan Surabaya. The sample is 100 pregnant mothers. The sample of the research was taken by random sampling. Mechanical analysis with structural equation model (Structural Equation Modelling - SEM) based covariance employed with AMOS software.

\section{RESULTS AND ANALYSIS}

The results descriptive of the behavior of the achievement of the MDGs 5 measured from antenatal visits and give birth to a decision either for home delivery or birth attendant. Data respondent characteristics such as age, education, occupation, parity, pregnancy risks, attitudes, knowledge, self-efficacy, family support and support cadres also analyzed by unilabiate.

\subsection{Characteristics of respondents}

Table 1 explains that among 100 pregnant women who visit antenatal care mostly in the healthy reproductive age, the majority of high school education and does not work as well as most ethnic Javanese.

Table 1. Characteristics of Respondent (Age, Education, Job, Region) in the Health Center Krembangan

\begin{tabular}{lcc}
\multicolumn{3}{c}{ South Surabaya in August-October 2015 } \\
\hline Variable & $\mathrm{N}$ & $\%$ \\
\hline Age & & \\
<19 years old & 15 & 15 \\
20-24 years old & 18 & 18 \\
25-29 years old & 57 & 57 \\
30-34 years old & 10 & 10 \\
>35 years old & 12 & 12 \\
Education & & \\
SD & 15 & 15 \\
SMP & 18 & 18 \\
SMA & 57 & 57 \\
PT & 10 & 10 \\
Job & & \\
Job & 13 & 13 \\
Jobless & 67 & 67 \\
Region & & \\
Java & 78 & 78 \\
Madura & 22 & 22 \\
Total & 100 & 100 \\
\hline
\end{tabular}




\subsection{Conduct the achievement of MDG 5}

Table 2 explains that of the 100 pregnant women doing most first-time visit in the first trimester (gestational age < 13 weeks), antenatal care visits adequately according to gestational age, planning to give birth in health facilities (health centers, hospitals, Maternity Clinic) and assisted by skilled health personnel.

Table 2. Distribution of Respondents by Category of Variable Utilization of Antenatal Care, Place of Delivery and Birth Attendant in the Health Clinic South Krembangan Surabaya in August-October 2015

\begin{tabular}{lcc}
\hline \multicolumn{1}{c}{ Variable } & $\mathrm{n}$ & $\%$ \\
\hline $\begin{array}{l}\text { Visiting antenatal K1 } \\
\text { doing }\end{array}$ & 95 & 95 \\
$\quad$ not doing & 5 & 5 \\
Visiting antenatal K4 & & \\
$\quad$ Adequate & 90 & 90 \\
$\quad$ No adequate & 10 & 10 \\
Birth & & \\
$\quad$ Health facility & 94 & 94 \\
$\quad$ Non Health facility & 6 & 6 \\
Birth & & \\
$\quad$ Midwife & 90 & 90 \\
$\quad$ Non midwife & 10 & 10 \\
Total & 100 & 100 \\
\hline
\end{tabular}

\subsection{Factors intrapersonal}

Table 3 illustrates that among 100 pregnant women who visit antenatal care mostly multigravida, use their own cost, relatively low-risk pregnancy, the third trimester of pregnancy in part, the majority of pregnant women have the knowledge, attitude and self-efficacy of good prenatal care.

Table 3. Distribution of Respondents by Category of Research Variables Intrapersonal in Health Center Krembangan South Surabaya in August-October 2015

\begin{tabular}{|c|c|c|}
\hline Variable & $\mathrm{n}$ & $\%$ \\
\hline \multicolumn{3}{|l|}{ Parity } \\
\hline Primigravida & 39 & 39 \\
\hline Multigravida & 61 & 61 \\
\hline \multicolumn{3}{|l|}{ Cost } \\
\hline personal & 69 & 69 \\
\hline BPJS & 31 & 31 \\
\hline \multicolumn{3}{|l|}{ Risk of pregnancy } \\
\hline Low Risk & 65 & 65 \\
\hline High Risk & 31 & 31 \\
\hline Very High & 4 & 4 \\
\hline \multicolumn{3}{|l|}{ Trimester } \\
\hline Trimester I & 21 & 21 \\
\hline Trimester II & 33 & 33 \\
\hline Trimester III & 46 & 46 \\
\hline \multicolumn{3}{|l|}{ Knowledge } \\
\hline Good & 93 & 93 \\
\hline Medium & 4 & 4 \\
\hline Lack & 3 & 3 \\
\hline \multicolumn{3}{|l|}{ Attitude } \\
\hline Good & 75 & 75 \\
\hline Medium & 25 & 25 \\
\hline Lack & - & - \\
\hline \multicolumn{3}{|l|}{ Self-efficacy } \\
\hline Good & 76 & 76 \\
\hline Medium & 23 & 23 \\
\hline Lack & 1 & 1 \\
\hline Total & 100 & 100 \\
\hline
\end{tabular}

\subsection{Factors interpersonal}

Table 4 explains that among 100 pregnant women who had antenatal care mostly has support both from family. Support in the form of emotional support, instrumental and emotional mostly good. 
Table 4. Characteristic Respondents by Family Support in Health Center Krembangan South Surabaya during August-October 2015

\begin{tabular}{lcc}
\hline \multicolumn{1}{c}{ Variable } & $\mathrm{n}$ & $\%$ \\
\hline Family support & & \\
High & 93 & 93 \\
Medium & 6 & 6 \\
Low & 1 & 1 \\
Emotional support & & \\
$\quad$ High & 97 & 37 \\
Medium & 3 & - \\
Low & - & 96 \\
Instrumental support & & 4 \\
High & 96 & - \\
Medium & 4 & 95 \\
Low & - & 5 \\
Informational support & & - \\
$\quad$ High & 95 & 100 \\
Medium & 5 & \\
Low & - & \\
\hline Total & 100 & \\
\hline
\end{tabular}

\subsection{Factors community}

Table 5 explains that among 100 pregnant women who had antenatal care mostly has support both from health cadre. Support in the form of emotional support, instrumental and emotional mostly good.

Table 5. Distribution of Respondents by Category Variable Health Cadre Support in Health Center Krembangan South Surabaya August to October, 2015

\begin{tabular}{lcc}
\hline \multicolumn{1}{c}{ Variable } & $\mathrm{n}$ & $\%$ \\
\hline Health cadre suppport & & \\
High & 83 & 83 \\
Medium & 15 & 15 \\
Low & 2 & 2 \\
Emotional support & & \\
High & 88 & 88 \\
Medium & 11 & 11 \\
Low & 1 & 1 \\
Instrumental support & & \\
High & 84 & 84 \\
Medium & 14 & 14 \\
Low & 2 & 2 \\
Informational support & & \\
High & 93 & 84 \\
Medium & 6 & 14 \\
Low & 1 & 100 \\
Total & 100 & \\
\hline
\end{tabular}

\subsection{Model development socio ecological models of health behavior towards achievement of MDG's 5 behavior}

Inferential research results with a structural equation modeling approach with Structural Equation Modelling can be unknown degree of influence between variables constructs research. The early models were developed in structural equation modeling analysis Social Ecological Model of Health Behavior is as follows in Figure 1.

Figure 1 explains that significant variables that influence the behavior of a delivery with the MDGs, so that these variables must be issued and carried out in order to form modal subsequent multivariate structural equation model of the most powerful with the strongest correlation estimates between variables empirically. 


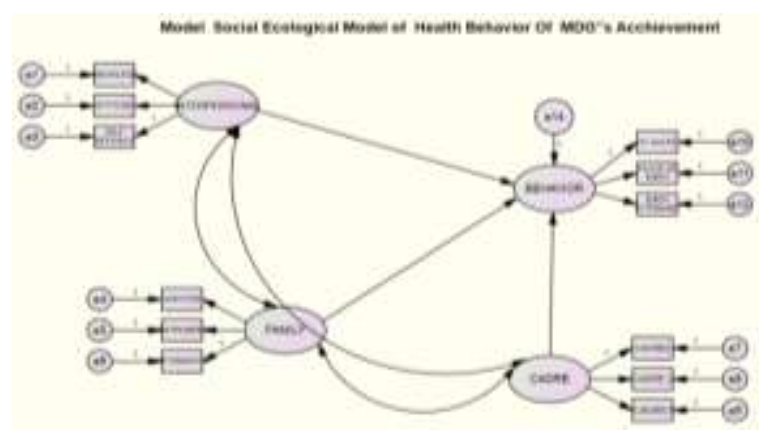

Figure 1. Initial model development socio ecological models of health behavior towards achievement of MDG's 5 behavior

End models was developed in structural equation modeling analysis Social Ecological Model of Health Behavior is as follows in Figure 2. Figure 2 and Table 6 explain that results of testing the model goodness of fit is known that the resulting model is an appropriate model used in the interpretation of the model because it has a model fit the criteria of empirical data generated by the study.

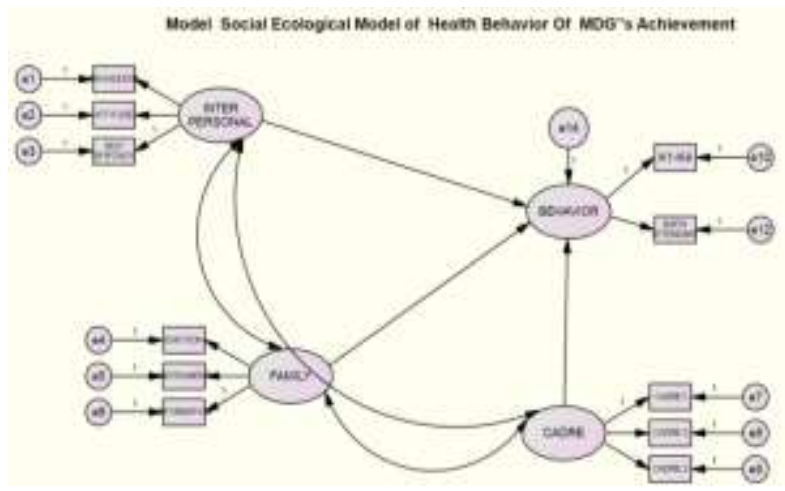

Figure 2. Model late model development socio ecological models of health behavior towards achievement of MDG's 5 behavior

Table 6. Evaluation Criteria for Goodness of Fit

\begin{tabular}{cccc}
\hline Goodness of Fit Index & Value Model & Cut Of Value & Explain \\
\hline RMSEA & 0.000 & $\leq 0.08$ & Fit \\
GFI & 0.772 & $\geq 0.09$ & Fit \\
AGFI & 1.000 & $\geq 0.09$ & Fit \\
CMIN/DF & 0.000 & $\leq 2.00$ & Fit \\
\hline
\end{tabular}

Focus Group Discussion conducted twice. The first meeting was held on October 28, 2015, 10:00 am at health center Krembangan South Surabaya along with 15 pregnant women with the Head of health center Krembangan South Surabaya, KIA coordinator midwife, midwives and midwife implementing wards. The second was a meeting held on 3 November 2015, at 13.00 with the Head of health center Krembangan South Surabaya, KIA coordinator midwife, midwives and midwife implementing wards. Basis for making strategic issues discussed in FGD is the exploration results in the analysis of significance.

Table 7 explains that focus group discussion indicate the importance of prenatal class, the home care program, health cadre empowerment and partnerships with shaman to improve the achievement of the utilization of antenatal care and delivery. 
Table 7. Basic Strategic Decision to Issue Discussed in the Group, the Pregnant Women, the Head of Health Center and Midwives

\begin{tabular}{|c|c|c|c|}
\hline No. & Indicator & Questioner Result & Issue strategy \\
\hline 1. & $\begin{array}{l}\text { Behavior achievement of the MDGs } 5 \text { as seen } \\
\text { from the Decision of the place of delivery. }\end{array}$ & $\begin{array}{l}\text { Non health facility (at home) : } \\
6 \%\end{array}$ & $\begin{array}{l}\text { - Home Care Program } \\
\text { - Prenatal Class }\end{array}$ \\
\hline 2. & $\begin{array}{l}\text { Behavior achievement of the MDGs } 5 \text { as seen } \\
\text { from the Decision of the midwife of delivery. }\end{array}$ & $\begin{array}{l}\text { Non health worker (Dukun) : } \\
10 \%\end{array}$ & $\begin{array}{l}\text { - Establish partnerships with shaman } \\
\text { - MOU with shaman }\end{array}$ \\
\hline 3. & The level of knowledge about prenatal care. & $\begin{array}{l}\text { Category } \\
\text { less : } 3 \%\end{array}$ & $\begin{array}{l}\text { Health Education Programs in Prenatal } \\
\text { Class based group trimester of pregnancy. }\end{array}$ \\
\hline 4. & Family support to conduct antenatal care. & $\begin{array}{l}\text { Category } \\
\text { Medium : } 6 \% \\
\text { less : } 1 \%\end{array}$ & $\begin{array}{l}\text { Health Education Programs in Prenatal } \\
\text { Class based group trimester of pregnancy } \\
\text { by involving the family. }\end{array}$ \\
\hline 5. & Support health cadres to conduct antenatal care. & $\begin{array}{l}\text { Category } \\
\text { Medium : } 15 \% \\
\text { Less : } 2 \%\end{array}$ & Refresher Training Program health cadres. \\
\hline
\end{tabular}

Knowledge of pregnant women affects the selection of the labor and birth attendants. Some studies showed that factors affecting pregnant women do ANC include age, education, knowledge, attitudes, cost, condition of pregnancy (no complaints), distance from health facilities [3-7]. A good knowledge about pregnancy and childbirth for pregnant women considered most of the 61 people $(61 \%)$ is thus possible multigravida category are often exposed to information through extension activities, pregnancy exercise group to get prenatal care, place and birth attendants.

The attitude of the majority of pregnant women $(75 \%)$ is good. Formation of attitudes does not happen by itself, but its formation through human interaction, both interactions within the group or outside the group. In case there is reference group and group membership interaction. Reference group is the group that became a grip people in his life. Membership group is a group which formally belonged to, have a relationship born [8]. Efforts are being made in the health center Krembangan South Surabaya there Prenatal classes through group pregnancy exercise, such activities can form an attitude to prenatal care, take a decision on the place and birth attendants in group membership and become a reference group for other pregnant women .

Self-efficacy of pregnant women mostly good (76\%), influence the election of ANC and birth attendants. A person who has high self-efficacy will have the confidence to be able to perform well, was able to see a difficult task as something that must be mastered. Self-efficacy can be established, acquired and developed through a pattern of behavior and the environment [3]. Activity prenatal classes in the health center to a vehicle that is appropriate to increase the self-efficacy of pregnant women in prenatal care with routine antenatal care, pregnant women also can observe the behavior of pregnant women who had experience as a learning process, because of mutual communication and sharing of experiences from the mother multigravida to mothers primigravida.

Family support is an indicator of interpersonal factors on the behavior of the achievement of MDG 5. Family support most (93\%) either. Good family support influences the behavior of the achievement of MDG 5 in terms of the selection of ANC and birth attendants. Forms of family support in the form of emotional support, instrumental and informational [6], [9]. The family that supports pregnant women in prenatal care, the impact on the achievement of antenatal care visits [10].

Support health cadres' majority (83\%) either. Health workers have an important role in helping health workers to detect the risk of pregnancy and childbirth safe drive, given the health cadres are in the society and have the time and frequency-face frequently with expectant mothers and families. The results of the study explained that the empowerment of ANC cadres to enhance the knowledge, attitudes and antenatal care visits [9], [11]. Overview of the new model is presented in Figure 3.

Figure 3 explains that there is development of new models of social theory of ecological models of health behavior in achieving the visit antenatal care and birth attendant. Behavior antenatal care and birth attendants' decisions shaped by factors of family support, health cadre as well as interpersonal factors include knowledge, attitude and self-efficacy. Results of other studies reveal that knowledge; attitudes affect the utilization of antenatal care [12]. 


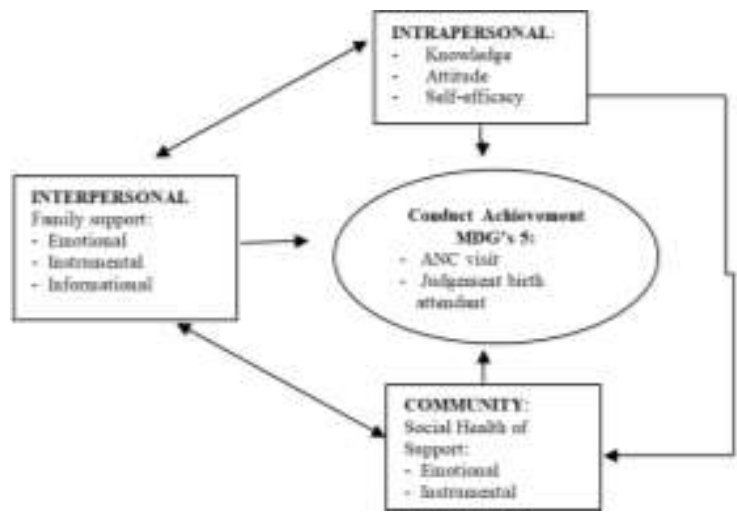

Figure 3. Development of new models of social ecological model of health behavior towards achieving MDG 5

\section{CONCLUSION}

The development of the social model of ecological models of health behavior to the behavior of the achievement of MDG 5 by the dominant factor is the construction of models intrapersonal factors which include knowledge, attitude and self-efficacy, interpersonal factors include the support of family and community factors include support for health cadres.

\section{ACKNOWLEDGEMENTS}

The model can be used in formulating strategies antenatal care interventions that increase knowledge, forming attitudes and self-efficacy through various activities such as prenatal classes or groups in pregnancy exercise.

\section{REFERENCES}

[1] A. Maftuchan, et al., "Reflection efforts to achieve MDGs 4 \& 5 in the region by 2015: A case study policy to reduce maternal and newborn children in Pasuruan, Takalar and Kupang," Prakarsa, Jakarta, 2013.

[2] Neupane S. and Doku D. T., "Determinants of time of start of prenatal care and number of prenatal care visits during pregnancy among Nepalese women," Journal of community health, vol/issue: 37(4), pp. 865-73, 2012.

[3] A. Bandura, "Health promotion from the perspective of social cognitive theory, Psychology and health," 1997.

[4] W. A. Gerungan, "Social Psychology," Bandung, Refika Aditama, 2004.

[5] U. L. Mardiyah, et al., "Factors Associated with the Use of Antenatal Care Pregnancy in Puskesmas Tempurejo Jember in 2013," e- Health Library Journal, vol/issue: 2(1), 2014.

[6] V. Sakinah and A. I. Fibriana, "Efforts to improve knowledge, attitude and visit antenatal care (ANC) pregnant women through empowerment of ANC cadres," Unnes Journal of Public Health, vol/issue: 4(1), 2015.

[7] Sarafino, "Health Psychology: Biopsichosocial Interaction, sixth edition," USA, John Wiley \& Sons, Inc, 2008.

[8] K. Beegle, et al., "Bargaining Power within Couples and Use of Prenatal and Delivery Care in Indonesia," California Center for Population Research University of California Los Angeles, UCLA, 2001.

[9] M. Mrisho, et al., "The use of antenatal and postnatal care: perspectives and experiences of women and health care providers in rural southern Tanzania," BMC Pregnancy and Childbirth, vol/issue: 9(10), 2009.

[10] S. E. Haque, et al., "Reproductive Health Care Utilization among Young Mothers in Bangladesh: Does Autonomy Matter? Women's health issues: official publication of the Jacobs Institute of Women's Health," Jacobs Institute of Women's Health, vol/issue: 22(2), pp. 171-80, 2012.

[11] S. Ahmed, et al., "Economic status, education and empowerment: Implication for maternal health service utilization in developing countries," Plos one, vol/issue: 5(6), pp. e11190, 2010. DOI: 10.1371, CIET Canada.

[12] Ye Y., et al., "Factors affecting the utilization of antenatal care," Nagoya Journal of Medical Science, vol/issue: 72(1-2), pp. 23-33, 2010. 


\section{BIOGRAPHIES OF AUTHORS}
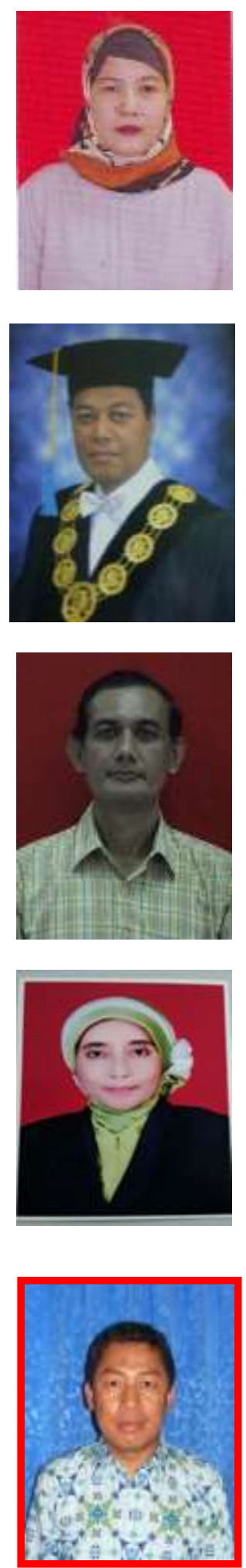

I am Hilmi Yumni. I was born on 5 May 1969 in Gresik. I studied in Bachelor of Nursing, Faculty of Medicine Airlangga University on 2002. I completed my master of Nursing Science speciality on Maternity Nursing at the Indonesia University on 2007 and pursuing doctor at School of Public Health, Airlangga University. I have many interests in maternity of nursing and reproduction of health. I had been Published on Electronic Journal Prakarsa Jakarta with Title: The reflection of MDGs 4 and 5, a policy analysis of the reduction of maternal and natality death rate at Pasuruan, Takalar and Kupang Districts in 2015. I am a lecture at the Nursing Program at Health Polytechnic of Surabaya, Indonesia

He is Prof. Dr. Fendy Suhariadi, MT., Psi. He is a Professor in Psychology Faculty, Airlangga University and he is a my promotor in doctoral programme. He was born on 17 January 1966 in Surabaya. He was studied in Bachelor of psychology, majoring on organization and industry psychology Airlangga University, on 1989. He completed Master of Technics at Bandung Technology Institute on 1993, and doctor of Industrial Machines and Management at the same university on 2002. He is a Keynote Speaker in $2^{\text {nd }}$ International Conference Psychology on Health, Educational, Social, Organizational Setting (ICP-HESOS 2015), title: Managing Change Through Organizational Development: a Pathway Toward Success in Indonesian University. ICP HESOS China 2015. He is a Director of LP3T Airlangga University (2015-Present).

He is Oedojo Soedirham, dr., MA., MPH., PhD. He is a Lecture in Department of Health Promotion and Behavior Sciences, Faculty of Public Health, Airlangga University. and he is a my co-promotor in doctoral programme. He was studied Doctor of Philosophy (PHD) Degree from The Departement of Sociology with special interest on Medical Sociology, University of Hawai'i at Manoa Honolulu, USA, on 1999. Before he studied Master of Arts (MA) Degree from The Department of Sociology with special interest on Medical Sociology at the same university on 1994. He was studied in Medical Doctor (MD) Degree from School of Medicine Airlangga University. Department Chair of Health Promotion and Behavioral Sciences, Faculty of Public Health, Airlangga University (2001 - Present).

She is Baiq Dewi Harnani R., SST., M.Kes. She is a lecture at the Nursing Program at Health Polytechnic of Surabaya, Indonesia. She was studied Diploma IV of Nursing, Airlangga University on 2002. Master of Public Health at Diponegoro University, Semarang on 2011. She was writing about Performance Analysis to Family Planning educators on the teenagers repructive health on 2010 .

He is Hasyim As'ari, S. Kep. Ns., M. Ked. He is a lecture at the Nursing Program at Health Polytechnic of Surabaya, Indonesia. He was studied in Bachelor of Nursing at Airlangga University on 2002. Master of Medicine on Airlangga University on 2010. He was Published about Lipid profile reduction using the extract mangosteen skin on Trubus Magazine in 2011. 


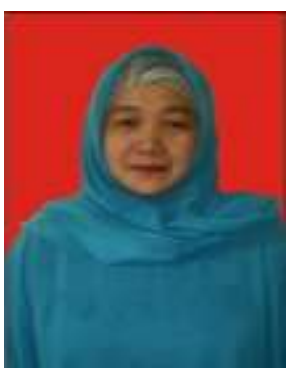

I am Noer Saudah. I was born on 15 September 1971 in Mojokerto. I studied in Bachelor of Nursing, Faculty of Medicine Airlangga University on 2002. I completed my master in medicine faculty Airlangga University on 2008. On 2015, I finished doctoral postgraduate programme pulict health Airlangga University. I have many interests in maternity of nursing and reproduction of health. I am a lectur on Institute of Helath Science Bina Sehat PPNI Kabupaten Mojokerto Indonesia 